\title{
Initiation and Performance of a Coating for Countering Chromium Poisoning in a SOFC-stack
}

\author{
Nielsen, Karsten Agersted; Persson, Åsa Helen; Beeaff, Dustin; Høgh, Jens Valdemar Thorvald; \\ Mikkelsen, Lars; Hendriksen, Peter Vang
}

\section{Published in: \\ E C S Transactions \\ Link to article, DOI: \\ $10.1149 / 1.2729329$ \\ Publication date:}

2007

Document Version

Publisher's PDF, also known as Version of record

Link back to DTU Orbit

Citation (APA):

Nielsen, K. A., Persson, Å. H., Beeaff, D., Høgh, J. V. T., Mikkelsen, L., \& Hendriksen, P. V. (2007). Initiation and Performance of a Coating for Countering Chromium Poisoning in a SOFC-stack. E C S Transactions, 7(1), 2145-2154. https://doi.org/10.1149/1.2729329

\section{General rights}

Copyright and moral rights for the publications made accessible in the public portal are retained by the authors and/or other copyright owners and it is a condition of accessing publications that users recognise and abide by the legal requirements associated with these rights.

- Users may download and print one copy of any publication from the public portal for the purpose of private study or research.

- You may not further distribute the material or use it for any profit-making activity or commercial gain

- You may freely distribute the URL identifying the publication in the public portal 


\title{
Initiation and Performance of a Coating for Countering Chromium Poisoning in a SOFC-stack
}

\author{
K.A. Nielsen, A. Persson, D. Beeaff, J. Høgh, L. Mikkelsen, P.V. Hendriksen \\ Department of fuel cell and Solid state chemistry, Risoe National Laboratory, Technical \\ University of Denmark, DK-4000 Roskilde, Denmark
}

Minimising transport of chromium from the metallic interconnect (e.g. of Crofer 22APU) to the cathode in a planar solid oxide fuel cell is done by application of a coating between the two parts. The coating is applied by slurry coating, and taken through stack initialisation it transforms into a stable and densely grown barrier layer, which minimises both the evaporation of chromium from the interconnect surface and the electrical contact resistance between the interconnect and the cathode. Between comparable stack element tests with and without coatings at $750^{\circ} \mathrm{C}$, the degradation rate in terms of power density decreased from $6.5 \%$ per $1000 \mathrm{~h}$ to very low levels ( $<0.84 \%$ per1000 hour) during the first 1000 hours of stack element testing when using such type of coating, indicating that the cathode poisoning from chromium has reached levels interesting for commercial development.

\section{Introduction}

The performance of SOFC fuel cell stacks based on planar cells with nickel anode, YSZ electrolyte, LSM cathode and metallic interconnect suffers from problems with chromium-containing vapours that originate from the interconnects on the air side being transported to the cathode, where they quickly deteriorate the electrochemical activity considerably. This phenomenon is known as chromium poisoning. Protective coatings may be applied to the interconnect to alleviate this problem. These coatings, typically of an electrically conductive spinel or perovskite structure, may be applied by a number of methods, usually as a stable or fully reacted coating before the metallic component is inserted and used in a SOFC stack (1-5). Other methods may be used to develop a stable but electrically insulating coating, e.g. of alumina (6), on the surface and then modifying certain portions of the coating or of the component for carrying the electrical current.

The present work was initiated to create similar coatings, but through reactions between a precursor coating and the interconnect steel. This allows the circumvention of the less attractive side effects of conventional coating techniques, such as high processing costs and poor adhesion between the coatings and the substrate after use and thermal cycling. It was also desirable to create a coating that could be applied by inexpensive methods, e.g. by slurry coating, at room temperature and subsequently be initiated during the stack initialisation such that only one temperature cycle is necessary. The ideal coating is constructed from both a barrier layer, which is thermally grown on the interconnect, that is impermeable to chromium and another layer able to hinder transportation of chromium-containing species to the cathode during start-up while the barrier layer is being formed and during stack operation if minor amounts of chromium is allowed to diffuse 
through the barrier layer either through the bulk material or along structural flaws within the coating.

To achieve its desired effect, the barrier layer should exhibit a negligible transport capacity for chromium, e.g. by being chromium-free or having very low chromium content. Reactive coatings that form such phases and still maintain sufficient electrical conductivity have been used by previous investigators $(7,8)$. One of the most promising combinations to date is the reaction between cobalt oxide and a manganese-containing steel (9, 10 ), because the resulting cobalt-manganese-spinel contains negligible traces of chromium and, additionally, has a suitable coefficient of thermal expansion that prevents the spallation of the coating.

The chromium getter component incorporated within to the second layer is more sparsely discussed in the literature. It has been shown $(11,12)$ that chromium readily bonds with elements with the perovskite structure in various cathode materials and on different electrolyte materials to create crystalline Cr-Mn-spinel phases, which can be formed at the interfacial surface between the electrolyte and cathode material or randomly distributed within the pore volume. Other potential getter materials may be sought among precursors for stable chromates, e.g. of lanthanum or strontium (13).

In order to develop such multi-layer coatings, the first screening of materials and designs was performed using small metal coupons, where potential coatings were exposed to different time and temperature profiles while monitoring their resistance across the scale interface over time. Subsequent to environmental testing, the microstructure of the reaction products were analysed by electron microscopy and elemental analysis. Promising coatings were deposited on button-sized metal samples, were inserted together with uncoated metal samples and a reference and tested against cathode samples deposited on 3electrode zirconia pellets while monitoring the time dependent progression of their electrical performance. Finally, coatings were applied to interconnect samples and inserted into a stack element testing environment and the stack performance including degradation was monitored during 1000-1200 hours.

\section{Experimental}

Thin $(0.3 \mathrm{~mm})$ sheets of a chromium-containing ferritic steel, Crofer 22APU [KruppThyssen VDM GmbH, Werdohl, Germany], were cut to shape before being treated with the surface coatings. Surface oxides on the interconnect metal inherent from the steel production were removed prior to coating by etching with HF acid and rinsing in water and ethanol, using an ultrasonic bath.

Perovskite powders, composed of strontium-doped lanthanum manganite, henceforth referred to as LSM, or strontium-doped lanthanum cobaltite, henceforth referred to as LSC, were produced by the glycine-nitrate route from nitrate solutions (14), calcined and milled to the desired particle size by ball milling. Other powders were obtained as analytical grade materials from commercial sources and milled to the desired particle size by ball milling. Particle size distributions were measured by a Beckman coulter I/S particle size analyser.

All coatings were applied at room temperature by spraying slurry mixtures, and the thicknesses of the coatings were controlled by both the solids content in the slurry and the number of subsequent coatings applied. 
For the small coupons used in the screening experiment, steel foils were cut in pieces of $20 \times 40 \mathrm{~mm}^{2}$ and perforated at both ends with holes, $\varnothing=6 \mathrm{~mm}$, having a centre distance of $28 \mathrm{~mm}$ and used for guiding pins to maintain the position of the samples in the subsequently formed stack. Coatings were applied on both sides for the coupons covering a squared area, $20 \times 20 \mathrm{~mm}^{2}$, centred on the coupons.

The coated coupons were separated by current distributor components of LSM and stacked in a furnace. Gold foils $(0.3 \mathrm{~mm})$ were positioned at both ends of the coupon stack and connected via gold leads to a power supply that was able to apply a constant current through all samples during the exposure test. Voltage probes, both spot welded onto the coupons and placed inside the current distributor components, were connected to a data acquisition system and the recorded voltage signals were used for calculation of the ohmic resistance across each interface throughout the experiment. The tests were carried out in stagnant air in a vertical furnace. The temperature profile included heating up to a binder burn-out step before heating to the test temperature $\left(750-950^{\circ} \mathrm{C}\right)$, which was then held for approximately 1000 hours. Finally, the temperature was reduced stepwise to be able to evaluate the temperature dependency of the resistance (activation energy) and the entire stack was subjected to three-to-five thermal cycles between the test temperature and approximately $150{ }^{\circ} \mathrm{C}$ in order to evaluate the resistance of the scale and the coat structure to larger temperature variations. The current direction was reversed in the stacks at the interval 650-880hours.

For the 3-electrode pellet tests, LSM cathodes were applied on to pellets made of $8 Y S Z$ and sintered. The samples were tested in air at $750^{\circ} \mathrm{C}$ in a 3-electrode set-up (single atmosphere) by applying a DC current of $0.5 \mathrm{~A} / \mathrm{cm}^{2}$. The resistance was measured between the reference electrode and LSM cathode, i.e. the sum of the electrolyte resistance $\left(R_{s}\right)$ and the cathode polarization resistance $\left(R_{p}\right)$. Uncoated and coated samples of Crofer 22APU were placed near the LSM cathodes of individual pellets and ran simultaneously with a reference sample where no steel was placed nearby.

For stack element testing, a planar anode-supported cell with a $16 \mathrm{~cm}^{2}$ active area was sandwiched between planar gas distributor components and a set of planar interconnect plates, which were connected to data acquisition and power circuit through a conventional 4-point circuit. Contact layers of nickel oxide and the multilayer cathode coating developed through this work were sprayed onto the anode and cathode faces, respectively, of the two interconnect plates. Cathode coating of LSM was used in reference experiments. The current collector/gas distribution plates used were, on the anode side, $\mathrm{Ni} / \mathrm{YSZ}$ pre-sintered at $1500^{\circ} \mathrm{C}$ and, on the cathode side, an LSM plate. The architecture of the both plates consisted parallel gas channels. The interconnect plates were fabricated from Crofer 22 APU steel and were cleaned by etching with hydrofluoric acid (HF) and rinsing in water and ethanol prior to the application of contact layers. The stack element was positioned horizontally in an alumina-fixture and heated at $180^{\circ} \mathrm{C}$ per hour through a binder burn-out step at $550-600^{\circ} \mathrm{C}$ while being supplied with air to both anode- and cathode compartments at flow rates of $5-6 \mathrm{ml} / \mathrm{min} / \mathrm{cm}^{2}$ surface area. After reaching $950^{\circ} \mathrm{C}$, the anode gas was changed to dry $9 \% \mathrm{H}_{2} / \mathrm{Ar}$ mixture for 15 minutes and $\mathrm{H}_{2}$ for the remainder of the test. The anode gas was humidified $\left(\sim 3 \% \mathrm{H}_{2} \mathrm{O}\right)$ when the stack temperature was reduced to $750^{\circ} \mathrm{C}$, prior to stack testing. The cathode gas remained air at a flow rate of 1401 per hour throughout the course of the test. 
Chromium poisoning of the cathode, if active, causes significant reduction of the maximum power density within a few hundreds of hours from initialisation, which was observed when using uncoated metal interconnects as a reference. The degradation was assessed by impedance spectroscopy and change in normalised voltage or area specific resistance over time.

Microstructures and the interfaces between components were evaluated using scanning electron microscopy (JEOL, JSM 5310) and energy dispersive X-ray analysis (EDS) on samples of polished cross-sections coated with a thin layer of elemental carbon.

\section{Results and discussion}

The electrical performance of a selected part of the coatings used during screening is shown in Table 1. The area specific resistance (ASR) data presented and discussed are referred to as scale interface resistance even though they include a contribution from the bulk resistance of a LSM current distributor plate, which has been determined on separate reference LSM plates to be between 2 and $3 \mathrm{mOhm} \cdot \mathrm{cm}^{2}$. In addition to the final ASRvalue, the calculated ASR-slope based on the final 100 hours oxidation is shown together with the change in ASR-values after repeated thermal cycling between $950^{\circ} \mathrm{C}$ and $150^{\circ} \mathrm{C}$.

Table I: Cathode coatings applied to Crofer 22APU listed together with the final values for area specific resistance (ASR) and the slope of the ASR-trace measured after $1000 \mathrm{~h}$ at $950^{\circ} \mathrm{C}$.

\begin{tabular}{llclc}
\hline $\mathbf{1}^{\text {st }}$ coat & $\mathbf{2}^{\text {nd }}$ coat & $\begin{array}{c}\text { ASR after } \\
1 \mathrm{kh} \\
\mathrm{m} \Omega^{*} \mathrm{~cm}^{2}\end{array}$ & $\begin{array}{l}\text { ASR-slope } \\
\text { at } 1 \mathrm{kh} \\
\mathrm{m} \Omega^{*} \mathrm{~cm}^{2} / \mathrm{kh}\end{array}$ & $\begin{array}{c}\Delta \text { ASR af- } \\
\text { ter thermal } \\
\text { cycling (\%) }\end{array}$ \\
\hline LSM & - & 15,7 & 217 & 290 \\
Co-based & LSM-based & $\mathbf{8 . 8 1}$ & 5,19 & 9 \\
LSC-based & - & 5,83 & $-0,91$ & 4 \\
Co-based & LSC-based & 5,26 & 1,61 & -9 \\
\hline
\end{tabular}

It may be observed that for the LSM-based coatings, resistance and degradation rates decrease significantly by applying a first layer where cobalt has been included, whereas this is not evident for the LSC-based coating system.

After 1000 hours aging at $950^{\circ} \mathrm{C}$, the coatings 2,3 and 4 in Table 1 show interface resistances in the range from 4 to $6 \mathrm{mOhm} \cdot \mathrm{cm}^{2}$, which is also at the lowest level that has been obtained for Crofer 22APU, regardless of the coating. This is probably indicative of the resistance across the protective chromia-scale that develops on the Crofer 22APU between the steel and any of the mixed spinel-layers that may form on top of it.

Figure 1 shows the final multilayer barrier structure on Crofer 22APU resulting from a double-layer coating after $1000 \mathrm{~h}$ at $950^{\circ} \mathrm{C}$ (left) and at $750^{\circ} \mathrm{C}$ (right). In both cases the metal phase, light gray at the left, is covered by a chromia layer, darker gray, and a MnCo-spinel layer, which are both well adhering and having a dense microstructure. The interface between the two layers comprising the scale is well defined in both cases and clearly visible when using back scattered imaging, although the thicknesses of the scales are quite different. The sample exposed to $950^{\circ} \mathrm{C}$ shows no traces of the pristine cobaltbased coating layer, but this is clearly seen as being only partially transformed on the 
sample exposed to $750^{\circ} \mathrm{C}$. The microstructure of the LSM-based coating layer seems to be slightly coarser after exposure to $950^{\circ} \mathrm{C}$ than to $750^{\circ} \mathrm{C}$.

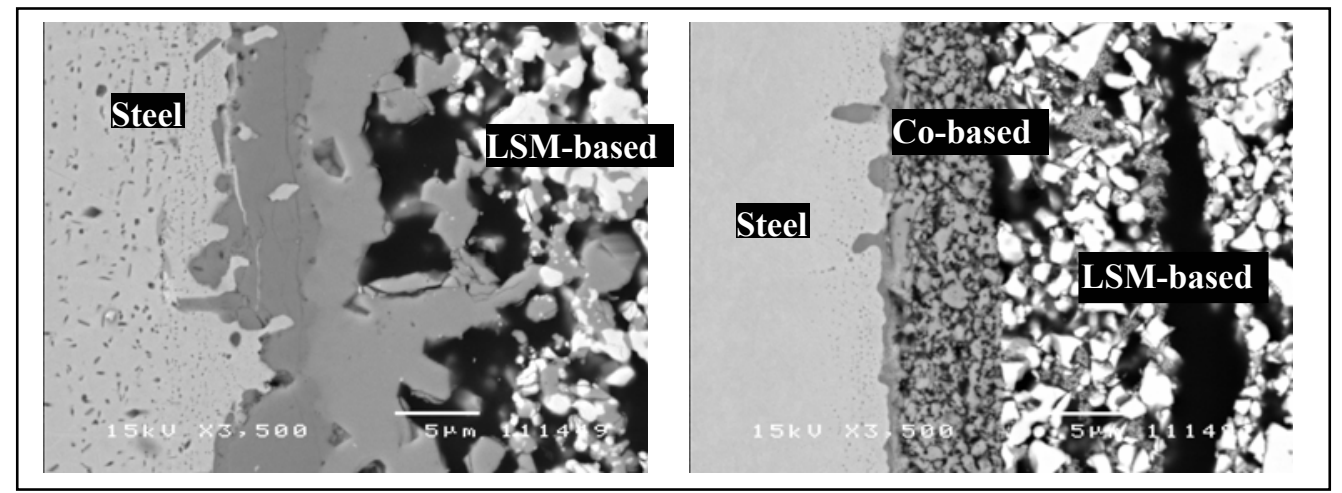

Figure 1: The microstructure of the thermally grown scale on Crofer 22APU after 1000 hours exposure to $950^{\circ} \mathrm{C}$ (left) and $750^{\circ} \mathrm{C}$ (right) for the double-layer coating with a first layer based on cobalt and a second layer based on LSM.

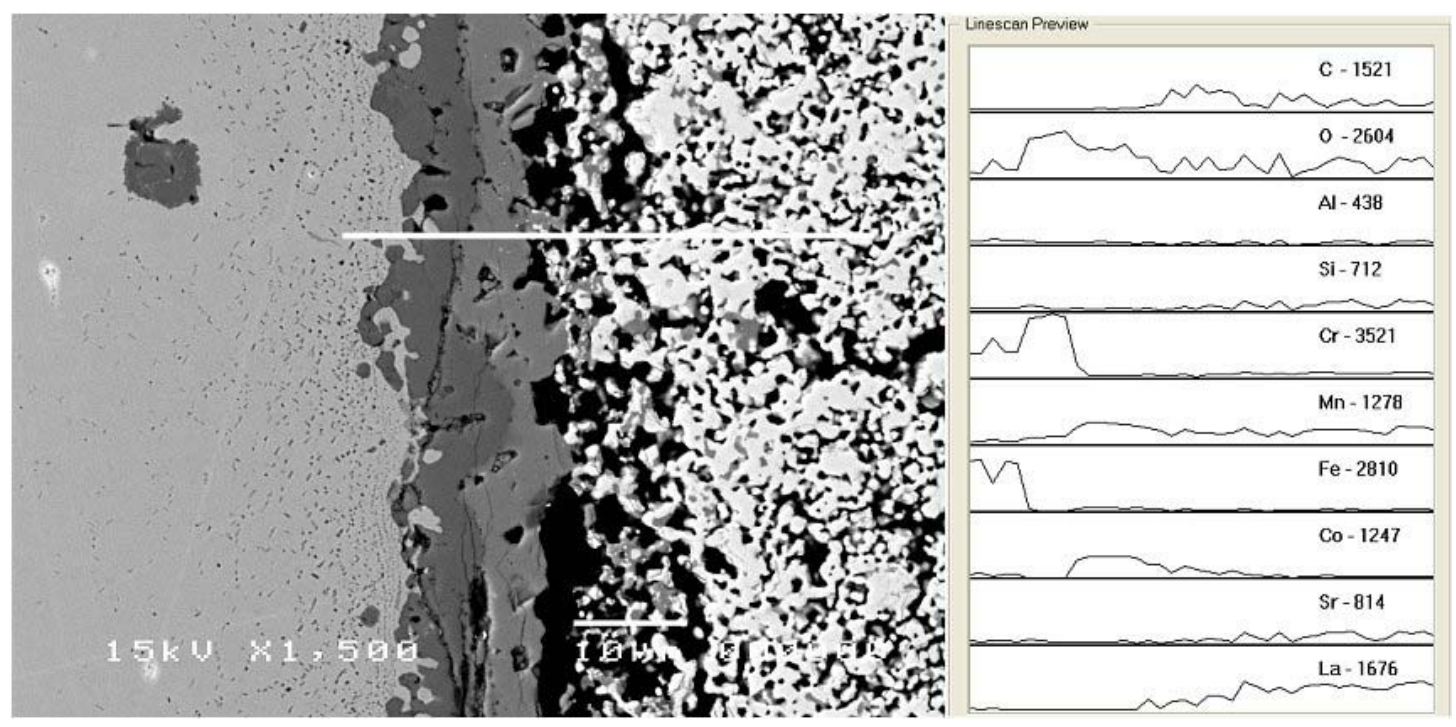

Figure 2: Micrograph obtained by back scattered electron imaging and showing the final multilayer barrier structure resulting from a first layer of cobalt-based coating and a second layer of LSM-based coating after $1000 \mathrm{~h}$ at $950^{\circ} \mathrm{C}$ and repeated cycling to $150{ }^{\circ} \mathrm{C}$. The result of a line-scan is shown at right, where the EDS-response from a selected range of chemical elements is recorded along a pre-defined path of the incoming electron beam, as indicated by the solid white line on the micrograph.

Figure 2 shows another example of the final multilayer barrier structure on Crofer 22APU resulting from a double-layer coating after $1000 \mathrm{~h}$ at $950{ }^{\circ} \mathrm{C}$ and repeated cycling to $150{ }^{\circ} \mathrm{C}$. The metal phase, light gray at the left, is covered by a 4-6 $\mu \mathrm{m}$ thick chromia layer, darker gray, and a 6-10 $\mu \mathrm{m}$ thick layer of a Mn-Co-spinel layer, which are also both well adhering and having a dense microstructure. The EDS response from line-scan shown at right in the figure shows a well defined interface between the chromia-scale and the overlaying spinel and that the spinel phase has a very low chromium concentration. 
The microstructure and composition of the barrier layer, preferably of the cobaltmanganese-spinel, depends not only on the amount of cobalt-based coating applied and the temperature, but also on the composition of subsequent coating layers. In Figure 3, the chromium concentration in the spinel layer, as expressed by a chromium-ratio, is shown as a function of the coating composition and the distance from the interface between the chromia-scale (the darker phase in Figure 2) and the spinel barrier layer (the lighter phase in Figure 2), which was formed on top of the chromia scale on the interconnect metal. The data was obtained by EDS analysis using an accelerating voltage of 15 $\mathrm{kV}$, so it is reasonable to assume that the relatively high values seen by the ordinate axis in the right graph of Figure 3 at distances less than 1 micron from the interface are influenced by the neighboring chromia scale rather than being a true value for the spinel. However, it is observed that the minimum chromium concentration in the spinel has been achieved by applying a single layer of cobalt-based coating or applying the combination of a cobalt-based under a LSM-based coating whereas replacing the LSM-part in the upper coating with a LSC-part failed to achieve similar results, even though the inner cobalt-based layers are nominally identical, cf. Figure 3 . The reason for obtaining identical results regardless of the presence of the second LSM-based coating layer in the right graph in Figure 3 may be the additional current distributor components, made from LSM, which enclose each sample.
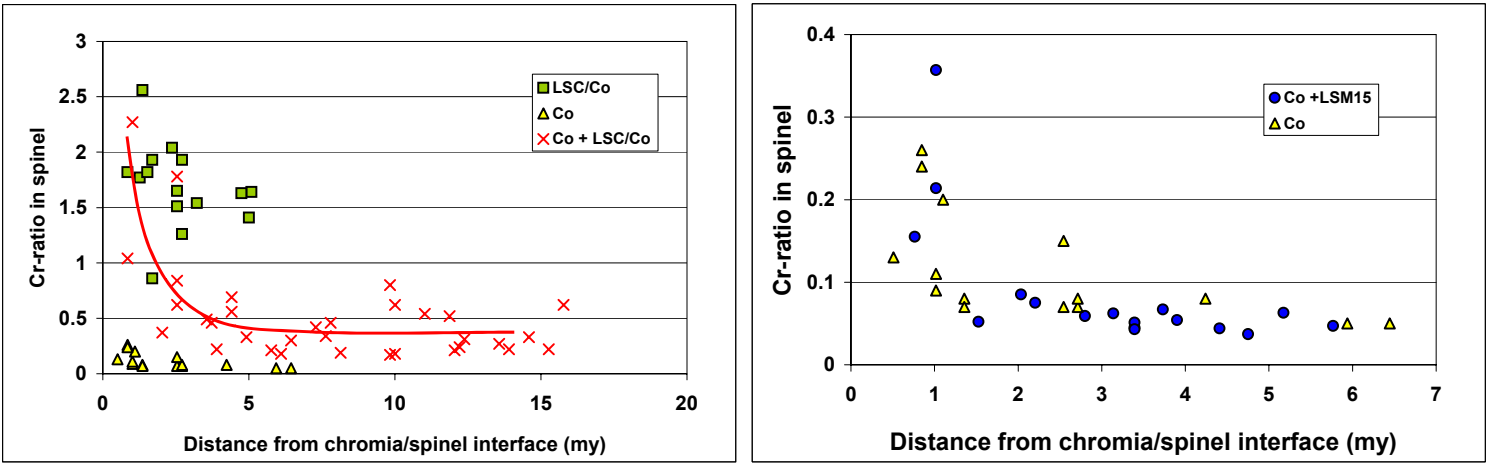

Figure 3: Chromium content in the outer spinel layer $\left(\mathrm{Me}_{3} \mathrm{O}_{4}\right)$ as a function of the distance from the inner chromia-scale. The scales were grown during 1000 hours in air at $950^{\circ} \mathrm{C}$ from LSC, LSM and Co-based coatings on Crofer 22APU.

The spinel compositions when grown in air on Crofer $22 \mathrm{APU}$ at $900^{\circ} \mathrm{C}$ for different times are listed in Table 2. The chromium concentration in the spinel, which has been grown below a cobalt-based coating, generally seems a little lower under LSM-based coatings than under the LSC-based coatings. Significantly higher chromium content is seen, though, when the first cobalt-based layer is absent. On aging for 4000 hours, the chromium concentration in the spinel layer increases slightly or even doubles in some cases. During the same period, the iron concentration seems to decrease slightly over time. As the manganese concentration in the spinel is significantly higher when using a LSM-based coating than when using a LSC-based coating, it has been concluded that the manganese content in the spinel partly stems from the coating and partly from the metal alloy, and that it may be beneficial to use manganese-containing coatings in order to facilitate the formation of a cobalt-manganese-spinel phase. It may also be noted that the spinel phase contains small amounts of iron only when cobalt has been present during growth, which may be concordant with the observation that the surface diffusion of chromium and therefore possibly also iron is significantly faster on spinels than on 
perovskites (15) and even chromia-forming alloys form an iron-rich spinel during the initial oxidation.

Elemental analysis showed that the chromium concentration in the spinel scale grown at $950{ }^{\circ} \mathrm{C}$ (see Figure 2) is significantly lower and equivalent to a composition of $\mathrm{Cr}_{0,1} \mathrm{Me}_{2,9} \mathrm{O}_{4}$ (see Figure 3) than in the scale grown at $900^{\circ} \mathrm{C}$, where it corresponds to a composition of $\mathrm{Cr}_{0,4} \mathrm{Me}_{2,6} \mathrm{O}_{4}$ or higher (cf. Table 2) and should be expected to give a much better protection against chromium diffusion from the metal scale to the cathode. Further studies will have to focus on the reaction and diffusion mechanisms that are responsible for such effect.

Table II: Average composition of the thermally grown outer spinel layer on samples of Crofer 22APU, when coated as specified. Measurements were done by EDS on polished cross sections of samples after 500, 10002000 and 4000 hour exposure to air at $900^{\circ} \mathrm{C}$

\begin{tabular}{|c|c|c|c|c|c|}
\hline 1st coat & 2nd coat & 500 h & $1000 \mathrm{~h}$ & $2000 \mathrm{~h}$ & $4000 \mathrm{~h}$ \\
\hline$\overline{\mathrm{LSM}}$ & - & $\mathrm{Cr}_{1.4} \mathrm{Mn}_{1.6} \mathrm{O}_{4}$ & $\mathrm{Cr}_{1.5} \mathrm{Mn}_{1.5} \mathrm{O}_{4}$ & $\mathrm{Cr}_{1.6} \mathrm{Mn}_{1.4} \mathrm{O}_{4}$ & $\mathrm{Cr}_{1.6} \mathrm{Mn}_{1.4} \mathrm{O}_{4}$ \\
\hline Co-based & LSM-based & $\mathrm{Cr}_{0.3} \mathrm{Mn}_{0.9} \mathrm{Co}_{1.7} \mathrm{Fe}_{0.1} \mathrm{O}_{4}$ & $\mathrm{Cr}_{0.4} \mathrm{Mn}_{0.9} \mathrm{Co}_{1.6} \mathrm{Fe}_{0.1} \mathrm{O}_{4}$ & $\mathrm{Cr}_{0.5} \mathrm{Mn}_{1.1} \mathrm{Co}_{1.4} \mathrm{O}_{4}$ & $\mathrm{Cr}_{0.7} \mathrm{Mn}_{0.8} \mathrm{Co}_{1.5} \mathrm{O}_{4}$ \\
\hline LSC-based & - & $\mathrm{Cr}_{1.4} \mathrm{Mn}_{0.6} \mathrm{Co}_{0.9} \mathrm{Fe}_{0.1} \mathrm{O}_{4}$ & $\mathrm{Cr}_{1.5} \mathrm{Mn}_{0.5} \mathrm{Co}_{0.9} \mathrm{Fe}_{0.1} \mathrm{O}_{4}$ & $\mathrm{Cr}_{1.3} \mathrm{Mn}_{0.7} \mathrm{Co}_{0.9} \mathrm{Fe}_{0.1} \mathrm{O}_{4}$ & $\mathrm{Cr}_{1.6} \mathrm{Mn}_{0.5} \mathrm{Co}_{0.8} \mathrm{Fe}_{0.1} \mathrm{O}_{4}$ \\
\hline Co-based & LSC-based & $\mathrm{Cr}_{0.4} \mathrm{Mn}_{0.7} \mathrm{Co}_{1.6} \mathrm{Fe}_{0.3} \mathrm{O}_{4}$ & $\mathrm{Cr}_{0.4} \mathrm{Mn}_{0.7} \mathrm{Co}_{1.7} \mathrm{Fe}_{0.2} \mathrm{O}_{4}$ & $\mathrm{Cr}_{0.5} \mathrm{Mn}_{0.6} \mathrm{Co}_{1.7} \mathrm{Fe}_{0.2} \mathrm{O}_{4}$ & $\mathrm{Cr}_{0.6} \mathrm{Mn}_{0.4} \mathrm{Co}_{1.8} \mathrm{Fe}_{0.2} \mathrm{O}_{4}$ \\
\hline
\end{tabular}

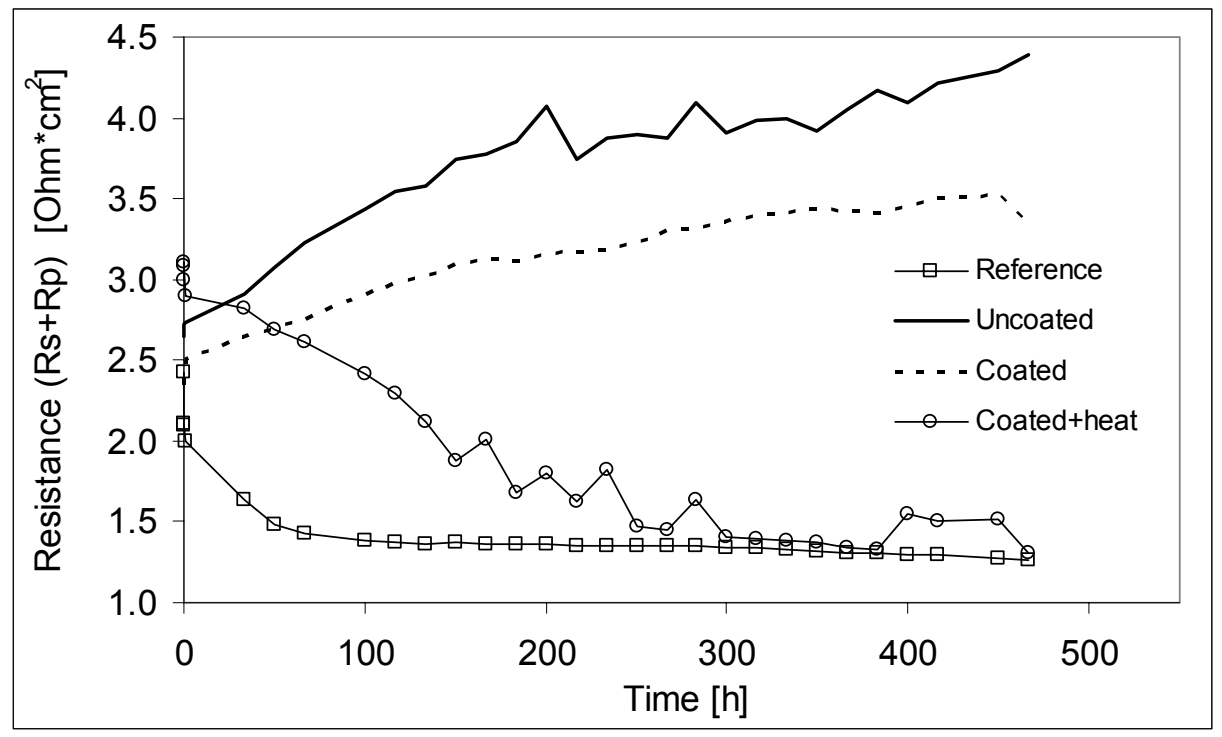

Figure 4: Resistance build-up in LSM composite cathodes on 3-electrode pellets when exposed to Crofer $22 \mathrm{APU}$ counterparts coated differently, se text, at $750^{\circ} \mathrm{C}$ and a current density of $0.5 \mathrm{~A} / \mathrm{cm}^{2}$.

The microstructure of the thermally grown scales under LSM-based coatings is significantly different from the microstructure of similar scales grown under LSC-based coatings. In the former scales, a distinct interface between the chromia scale and the spinel scale is visible, as shown in Figure 2, whereas the transition between these two scales is almost undetectable in the latter type of scales, as shown in Figure 5, from which it is also seen that the scale is not as continuous and well adhering as for the LSM-based coatings. It may also be seen that the chromia scale is much thinner in the LSC-based 
coatings, which corresponds well with the observation that the electrical resistances of LSC-based barrier layers are lower compared to the LSM-based counterparts (see Table 1) and that both the iron and the chromium concentrations are highest in the LSC-based scales (see Table 2).

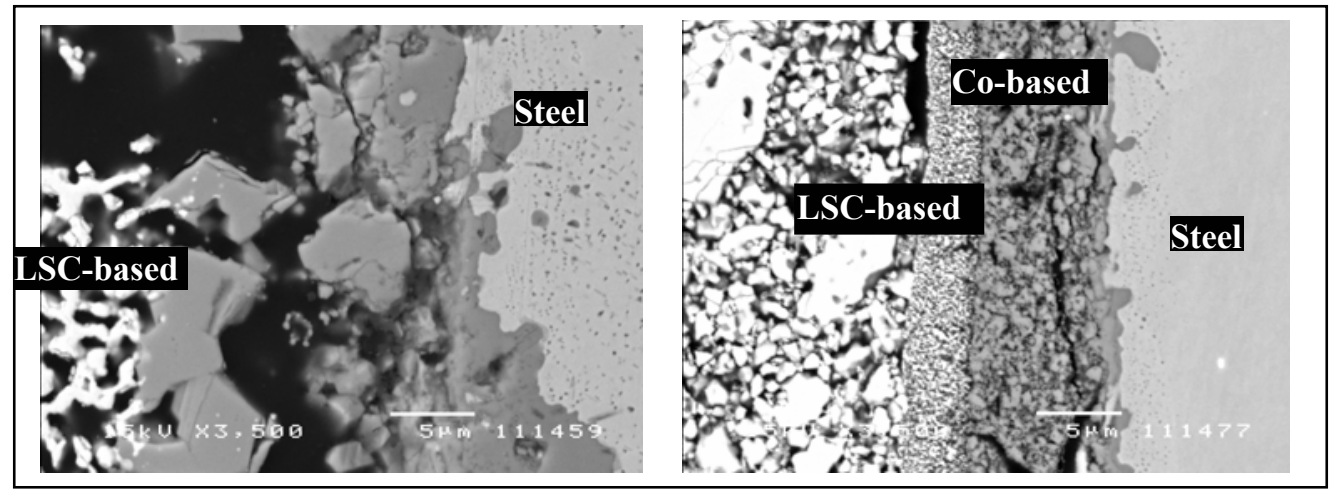

Figure 5: The microstructure of the thermally grown scale on Crofer 22APU after 1000 hours exposure to $950^{\circ} \mathrm{C}$ (left) and $750^{\circ} \mathrm{C}$ (right) for the double-layer coating with a first layer based on cobalt and a second layer based on LSC.

In order to test the barrier layer effect of the two-layer coating based on cobalt and LSM against chromium poisoning of the LSM cathode, three differently coated samples and a reference were tested in the 3-electrode set-up. The variation in resistance versus time is shown in Figure 4. It is seen that a coated sample, which has been heat treated at $950^{\circ} \mathrm{C}$ prior to this experiment, performed at the same level as the reference sample after $300 \mathrm{~h}$, where no metallic counterpart was used. Both the uncoated and coated, but not heat treated samples cause a large degradation compared to the reference sample. This indicates that the cathode is protected from Cr-poisoning if the double layer coating on the steel has been initiated at $950^{\circ} \mathrm{C}$, concordant with the results shown in the Figures 1-3.

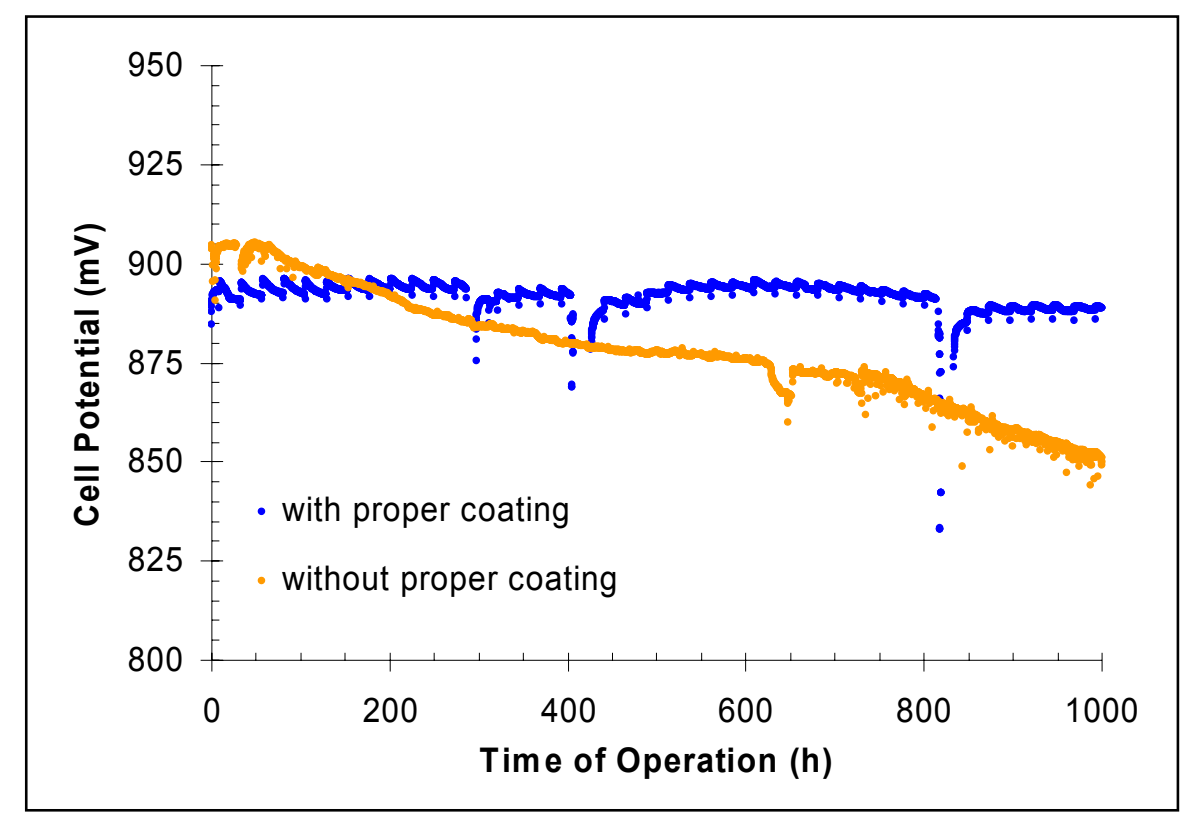

Figure 5: Voltage behavior versus time of two stack element tests for the first 1000 hours at a current density of $250 \mathrm{~mA} / \mathrm{cm}^{2}$. 
Finally, stack element tests were performed in order to evaluate the effectiveness of the developed cathode face coating on the interconnect during cell operation. Figure 5 shows the voltage behavior versus time of two stack element tests, one with a double layer coating based on cobalt and LSM and one with a single layer LSM coating during the first 1000 hours, run at a constant current density of $250 \mathrm{~mA} / \mathrm{cm}^{2}$. The "wavy" appearance of the curve for the cathode face coated sample is a result of IV-measurements automatically performed every 24 hours. For clarity, these data points have been removed.

This stack element had an initial stack potential at $898.5 \mathrm{mV}$. By 300 hours this had actually improved somewhat to $899.3 \mathrm{mV}$. A software malfunction in the control program resulted in the stack going to open circuit conditions at $t=300 \mathrm{~h}, t=415 \mathrm{~h}$ and $t=$ $820 \mathrm{~h}$. After each OCV event, the cell voltage was found to have dropped about $2 \mathrm{mV}$, but slowly regained the potential. The stack element showed a relatively constant potential of $891 \mathrm{mV}$ at the end of the testing period, equivalent to a $0.8 \%$ reduction of the potential over 1000 hour, which is almost an order of magnitude lower than for the case where the interconnect only had been coated with LSM, which showed a similarly obtained reduction of $6.5 \%$. For comparison, testing single cells in a chromium-free environment showed similar degradation in the range of $0.2-0.5 \%$ per 1000 hours, which is also close to the detection limit.

The stack element with cathode face coating showed a relatively constant area specific resistance (ASR) at $600-610 \mathrm{mOhm} \cdot \mathrm{cm}^{2}$ until the third occurrence of the program glitches when it changed to $640-645 \mathrm{mOhm} \cdot \mathrm{cm}^{2}$ which was held until $t=1000$ hour. The change could not be ascribed to increased interface resistances as these were recorded at nearly constant levels, around 19 and $3 \mathrm{mOhm} \cdot \mathrm{cm}^{2}$, for the cathode and anode interfaces respectively.

From the polished cross section of the cathode face coated stack element it was seen that the first cobalt-based layer has evidently sintered and reacted with manganese to form a manganese cobalt spinel. The LSM top coat does not appear to be significantly depleted of manganese. Most interesting is the formation of a dense chromium oxide scale at the reaction interface. The scale itself is not necessarily important but the fact that there is no detectible chromium beyond this layer is, which is in agreement with the results shown in Figure 3. It would appear that the cobalt-based layer and the subsequent formation of the dense spinel inhibit the diffusion of chromium.

\section{Conclusion}

Controlling factors for the formation of the desired chromium-free barrier layer have been illustrated. Both the reaction temperature and the composition and amounts of the different layers in the coating seem to be important. For example, in order to develop a microstructure for the barrier layer that possesses a minimum electrical resistance, i.e. where the dense, chromia-lean spinel-layer has good contact to the second, porous perovskite layer, the amount of material in the first layer has to be minimised. On the other hand, in order to develop a spinel-layer with low chromium content, sufficient amount of reactants, e.g. Cobalt-based oxides have to be available for the layer formation by which the chromium content may be reduced by a factor of two. The optimum amount of cobalt is much dependent on the reaction temperature, but most important seems to be 
the influence of the reaction temperature for scale growth on the chromium concentration in the spinel scale, as the scale grown at $950{ }^{\circ} \mathrm{C}$ has a significantly lower chromium concentration, corresponding to a composition of $\mathrm{Cr}_{0,1} \mathrm{Me}_{2,9} \mathrm{O}_{4}$, than the scale grown at $900^{\circ} \mathrm{C}$, where it corresponds to a composition of $\mathrm{Cr}_{0,4} \mathrm{Me}_{2,6} \mathrm{O}_{4}$.

Testing if the barrier layer effectively hinders chromium poisoning showed that between comparable stack element tests with and without proper coatings at constant temperature and current density $\left(750^{\circ} \mathrm{C}\right.$ and $250 \mathrm{~mA} / \mathrm{cm}^{2}$ respectively), the degradation rate in terms of power density decreased from $6.5 \%$ per 1000 hour to very low levels $(<0.84 \%$ per1000 hour) during the first 1000 hours of stack element testing when using a double layer coating.

\section{Acknowledgments}

The work was part of the DK-SOFC project funded by the Danish Power Suppliers (ELKRAFT system) and the Danish Energy Authority under contract no: 2006-1-6342, who are acknowledged together with Topsoe Fuel Cells A/S and the staff at Risø National Laboratory for their inspiring collaboration.

\section{References}

$1 \quad$ F. Tietz, et al., DE 10306649 A1 (2004)

2 F. Tietz, and M. Zahid DE 10306647 A1 (2004)

3 D.B. Hilliard (2003) US2003194592-A1

$4 \quad$ N. Orlovskaya et al. J, Am. Cer, Soc 87, 1981-1987 (2004).

$5 \quad$ X. Chen et al. Solid State Ionics 176. 425-433 (2004).

6 W.J. Quadakkers WO 97/23006 (1997).

$7 \quad$ K. Fujiata el al. J. Power Sources 131, 261-269 (2004).

8 M. Larring and T. Norby , J. Electrochem. Soc. 147. 3251-3256 (2000),

9 A. Hansson, Oxides in the Co-Cr-Fe-O system, Ph.D thesis, Technical University of Denmark, 2800 Lyngby (2004)

10 M. Zahid et al. in Proceedings of The $6^{\text {th }}$ European Fuel Cell Forum M. Mogensen editor, pp.820-827 (2004).

11 S.P. Jiang et al. J. Eur Cer. Soc. 22, 361-373 (2002).

12 Y. Matsuzaki and I. Yasuda J. Electrochem. Soc. 148, A126-A131 (2001).

13 Tokyo gas (JP2002367615-A)

14 L. A. Chick et al., Materials Letters , 10, 6-12 (1990).

15 M.C. Tucker et al., J. Power Sources, 160, 130-138 (2006). 